\title{
$\begin{array}{ll}\text { Research Square } & \begin{array}{l}\text { Preprints are preliminary reports that have not undergone peer review. } \\ \text { They should not be considered conclusive, used to inform clinical practice, } \\ \text { or referenced by the media as validated information. }\end{array}\end{array}$
}

\section{Development and Validation of a Shared Governance Feasibility Instrument in Nursing Schools in Iran}

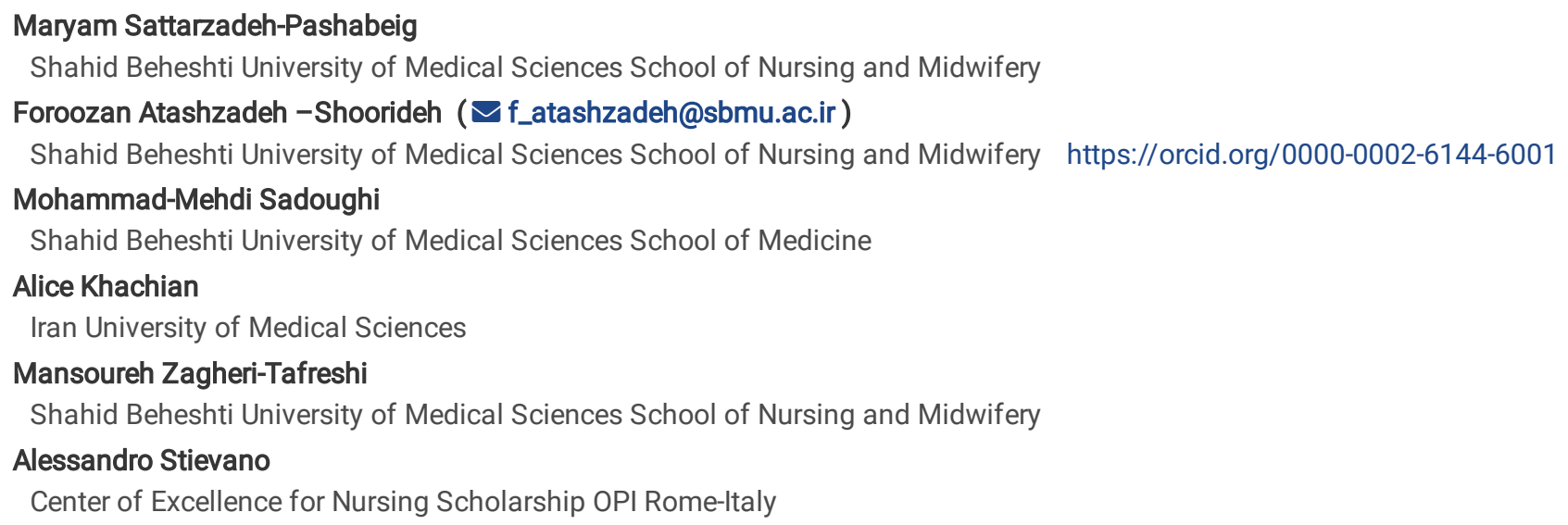

Research article

Keywords: Nursing education, Nursing schools, Psychometrics, Shared governance

Posted Date: March 25th, 2020

DOI: https://doi.org/10.21203/rs.2.19131/v2

License: (c) (i) This work is licensed under a Creative Commons Attribution 4.0 International License. Read Full License

Version of Record: A version of this preprint was published at BMC Nursing on May 20th, 2020. See the published version at https://doi.org/10.1186/s12912-020-00433-x. 


\section{Abstract}

To develop and validate a shared governance feasibility instrument in schools of nursing in Iran with respect to the nature of the profession and the sociocultural context of the Iranian community.

Background: Nursing schools are liable to the application of shared governance due to the presence of various expert educational groups within the school that necessitates reciprocal cooperation. Since the concept of shared governance is culture-based and given that no full-fledged study has been conducted on shared governance in Iran, the development of a suitable shared governance feasibility instrument is rendered as mandatory.

Methods: This sequential exploratory mixed method study consisted of two qualitative and quantitative parts was accomplished 2016-2019. First, the primary items were extracted through extensive review of literature and qualitative interviews and underwent psychometric validation using a methodological approach. Face, content, construct validity, reliability of the instrument was established were done.

Results: 150 items were distilled from the first stage of the study, was reduced to 70 after establishing face and content validity, and primary reliability. Exploratory factor analysis resulted in 52 items covering the two factors "shared atmosphere and culture" and "infrastructural prerequisites". These two factors accounted for $78.6 \%$ of the total variance of the questionnaire. In calculating the final reliability coefficient of the instrument, Cronbach's alpha and Omega were 0.981 and 0.805 , respectively. The results showed an ICC of 0.91 indicating high reliability of the developed instrument with standard error of measurement (SEM) of 10.43. Finally, the items underwent weighting via scoring by considering item weights due to differences between the two methods.

Conclusion: "Shared governance feasibility instrument" can provide a new insight to organizational performance for all policy-makers and beneficiaries of higher education. This not only leads to the use of intelligence and capabilities of the beneficiaries, but also aids in faster movement toward achieving organizational goals. Implications for Nursing Management : This study and the developed instrument may serve as guide for the feasibility of implementing shared governance to assess management styles and performance in higher education centers.

\section{Background}

Shared governance is a structure in which the individuals of one organization do the decision-making process. This allows them to take accountability, responsibility, and ownership of decisions. Although shared governance is typically referenced regarding nursing practice, it can be adapted to higher education[1]. Definition of Shared governance is difficult because it is utilized differently within each organization[2]. Organizations that create a participatory environment for staff are more likely supporting of a shared vision and sense of empowerment among team members[3]. A sense of belonging can create a culture in which employees are more engaged in their work. Organizational cultures with high levels of engagement and satisfaction can expect greater productivity and retain more motivated employees[2]. In spite of these advantages, schools and universities are often inefficient to creating engagement opportunities among faculty and staff[4].

Iranian higher education institutes have expectations of their faculty members, but they have not yet clearly defined the faculty roles. The professional roles for a faculty in universities are generally three parts such as teaching, research, and executive service. In the recent years, Ministry of Health and Medical Education added cultural-educational-social role to these roles [5]. These changes have enhanced the importance of effective internal governance in such institutes [6]. Shared governance has been one of the important management strategies for many years in other disciplines such as commerce, education, political sciences, and religious sciences, who have benefited from the application of its principles [7].

Cleland (1978) introduced the shared governance model into the nursing literature, with the concept of an academic model of governance by faculty members. This model incorporated the interests of all groups in organizational policy-making, by distribution of power among different groups in the organization [8]. Although, shared governance have been utilized in many countries such as America[9-11], England[12], Pakistan[13], China[14], Jordan [15]and Jamaica[16], but the models and indicators of shared governance were criticized many times[3, 4, 13, 17]. In addition, no suitable instrument has been found by authors to measure the feasibility of shared governance at universities in the world.

Shared governance is a strategy that assigns faculty members a position similar to that of managers, enabling them to take part in decisionmaking that, in turn influences managers' performance [15]. The common characteristics of various definitions of shared governance are lack of dependence in performance, responsibility, empowerment and development, and contribution and collaboration in decision-making. The process by which these goals are reached may differ considerably among organizations $[10,18]$.

Shared governance in nursing is a way of providing individuals with a position for decision-making in their performance, like that of managers [8]. The concept of shared governance has been defined in a study in Iran as being like "several souls in one body" that not only shares the above-mentioned characteristics, but has also considered spirituality in the organizations as a feature of such shared governance $[15,18]$. Nursing education predisposes to training professional nurses who can use this capacity to investigate and recognize the health status of 
people and who can will and provide care in different fields to persons, families, and community [8]. Decision-making in nursing schools and many higher education centers is commonly performed in a hierarchical order that is the antithesis of shared decision making [10]. In the present educational system in Iran, faculty members have no role in policy-and decision-making, although the duties of education and research, and the communication with students rest on their shoulders [15]. For greater efficiency, it would seem appropriate that State universities should move their governance structure towards shared responsibilities [13]. Most shared governance models implemented in education centers worldwide are based on seven indicators introduced by the seminal Ramo's shared governance model (2001). These represent the institutional climate for governance, institutional communication, joint decision-making, the role of the institutional governing board, the role of the institutional president, the role of the faculty at the institution and assessing the structural arrangement for governance [19]. Ramo's model may not be applicable everywhere, and the existence of different cultures in different countries has brought about variable outcomes in implementation of shared governance [16]. Hence, it appears that to implement shared governance, it is necessary to first carry out investigations based on the organizational culture governing any organization to determine accurately the concept and the structure of shared governance [8]. An instrument named the "American Association of University Professors Indicators of Sound Governance" (AAUPISG) was introduced on the basis of Ramo's (1996) indicators of shared governance to investigate the rate of correspondence between the performance of higher education centers and the national standards of shared governance [20].

Most studies conducted on shared governance have either not used specialized shared governance instruments [15], or utilized the AAUP indicators in its original or adjusted forms [14, 21]. In some cases, only some part of the above-mentioned instrument has been used [13]. Additionally, reviewing the literature we found that a no fully-fledged study explored or reported the feasibility of implementation of shared governance in Iranian educational centers[7, 22]. As the concept of shared governance has not been widely recognized in Iran and elsewhere, the investigation of whether this is, a feasible construct also in Iran demanded to develop an instrument. In the present study, which is part of a larger scale study on the concept of shared governance in the sociocultural contexts of the Iranian community, we have developed and validated psychometrically a suitable instrument for assessing feasibility of implementation of shared governance as a construct in nursing schools affiliated to three major medical universities in, Tehran. The aim of this study is developing and validating a shared governance feasibility instrument. In this regards, the question of this research were "what is meaning of shared governance concept in nursing schools?", and "does the designed tool have optimal validity and reliability?"

\section{Methods}

\subsection{Design}

This is a sequential exploratory mixed method study, conducted 2016-2019. In this research, tool development consisted of two qualitative and quantitative stages initiated with the qualitative stage and followed by the quantitative follow up. Hybrid concept analysis including the theoretical stage, filed practice, and final analysis were carried out in the qualitative stage. Review of literature was done in the theoretical stage. In the field practice, 13 participants with purposive sampling method and underwent semi-structured interviews. The definition of shared governance, characteristics, antecedents, and consequences were extracted from the results of concept analysis. Using the findings of the first stage, the themes were distilled and developed into an instrument that was subsequently measured psychometrically using methodology approach.

In quantitative stage of the instrument development, face and content validities, exploratory factor analysis (EFA), and reliability were used (Figure 1).

\subsection{Participants}

A total of 22 articles obtained from review of the literature were initially analyzed. Thereafter, during a fieldwork phase, 13 participants including one member of a nursing board in Ministry of Health $(\mathrm{MOH})$, three intermediary managers of medical universities in Tehran city, and nine faculty members of nursing schools were interviewed. They were selected with a purposive sampling method designed to ensure maximal variety in age, gender, specialty, and work experience in higher education centers [18, 22]. For the quantitative psychometric validation of the instrument, 10 managers, and faculty members of the nursing schools participated in the face validation, 10 in the content validation, 30 in the primary reliability establishment and 194 faculty members in the construct validation and final reliability processes.

For construct validation, at least three participants were required for each item in the quantitative stage. 250 questionnaires were distributed to faculty members of nursing schools five of the biggest or highest schools in our ranking system selected with a convenient sampling method. The inclusion criteria were voluntary participation and at least two-year work experience as full-time faculty member in the school. Of these 250 questionnaires, 194 completed questionnaires were returned and these were analyzed for construct validation (response rate=78\%).

\subsection{Data collection}


Concept analysis and determination of final operational definition of context-based shared governance using hybrid concept analysis was done [18]. To extract items from the available literature in the theoretical stage, the related papers were searched with the keywords "tool/instrument/ questionnaire, faculty member, higher education, and shared governance, feasibility, psychometric" using the databases "Google Scholar, PubMed, Science Direct, and Eric" in the time interval 1990-2017. Simultaneously, Persian databases like MedLib, Scientific Information Database (SID), Magiran, Iran Doc, and Iran Medex were searched with Persian keywords for shared governance: these searches did not return a single related paper. Of 349 papers retrieved from the initial search, 22 articles related to exact research goals and related to shared governance instruments and guidelines. In the fieldwork phase, the first author performed semi-structured deep interviews with 13 participants to extract the intended items [18, 22]. The inclusion criteria consisted of any studies that were in Persian or English language, systematic review, qualitative and/or quantitative, integrative and psychometric, and full-text articles. The studies that did not relate to college or universities were excluded.

After analyzing the data obtained from the theoretical stage and fieldwork phase, integrating the findings and extracting codes and categories using inductive-deductive approach, the items pool, consisting of 150 items including characteristics, antecedents, and consequences of the concept analysis stage, entered psychometric validation stage.

The instrument underwent quantitative and qualitative face and content validation by 10 faculty members; then, it underwent primary reliability establishment and item analysis and some items had been changed or omitted. Then, the questionnaire was distributed to faculty members with 70 items.

\subsection{Data analysis}

Data were analyzed by the method of Schwartz-Barcott \& Kim [23]. Conventional content analysis by Graneheim \& Lundman was used to determine the concepts and to extract codes and categories [24]. The full text of each paper in the theoretical stage and each interview in the field-work phase were considered as an analysis unit [25]. Then, each article was read three times to arrive at an agreed general content. The primary codes were then extracted as explicit and implicit concepts. In the next stage, similar codes (obtained from explicit and implicit concepts) were classified as subcategories, which in turn, were put into a group. The categories were subsequently labeled [24]. In the final stage, the data obtained from the theoretical stage and fieldwork phase were merged and the item pool was obtained. In the third part of the study, the methodological approach was applied to determine the psychometric properties of the first version of the instrument with 150 primary items. Having applied the corrections in the qualitative stage, quantitative face validity was established by measuring item impact. To make sure that the items measured the intended construct, content validation was done both quantitatively and qualitatively. To explore CVR, 10 managers and faculty members were asked to assess the necessity of each item. To survey $\mathrm{CVI}$, the managers and faculty members were asked to express their opinions about the rate of relatedness of each item with the intended construct [26]. Regarding raters consensus on item relatedness, the modified Kappa 1 statistic [27] was used; this provides instrument developers with information on the degree of consensus without chance ratio. A corrected Kappa statistic greater than 0.74 was rendered as excellent, between 0.6 and 0.74 as good, and smaller than 0.6 as poor [28]. Colton \& Covert (2007) mentioned item analysis (IA) as one way of construct validity assessment; to examine construct validity, the correlation between each item and other items and the whole instrument was performed. To investigate the primary reliability of the instrument before validation, the internal consistency coefficient (Cronbach's alpha) was used. In this study, factor analysis in construct validation [26] and exploratory factor analysis (EFA) with maximum likelihood by the use of oblique rotation of the Promax type was utilized to determine the degree to which the developed instrument measures the concept of shared governance. Also, EFA was used to determine the relations among the latent and observed variables and then the significance and severity of these relations [29]. By doing this, the three criteria of Kaiser's criterion, Scree plot and cumulative variance percentage determined by extracted factors were used. The KMO statistic was estimated to test sample volume sufficiency in which 0.8 and greater was rendered as suitable [29]. Moreover, scree plot was plotted to determine the number of factors. Lying of factors out of the formed horizontal line was rendered as reference [30].

In this study, three samples per item were rendered as sufficient in factor analysis [31]. The study sample consisted of faculty members at nursing schools of major Iranian medical universities selected based on inclusion criteria as mentioned before. The developed instrument was completed via self-report. Considering that the instrument contained 70 items, given the ratio of 3 samples per item, completion of at least 210 questionnaires was necessary\{Plichta, $2013 \# 20\}$. On this basis, considering a probable rate of deficient or unreturned questionnaires, 250 written questionnaires were distributed to faculty members of nursing schools, of which 56 questionnaires were not returned. Hence, 194 completed questionnaires (response rate 78\%) were collected. SPSS20 was used in data analysis. Finally, the reliability of the instrument was established using both internal consistency and stability. To estimate internal consistency, Cronbach's alpha and conventional odd/even splithalf reliability were used. Additionally, test-retest reliability and intra-class correlation coefficient with 2-week interval was used on 30 faculty members to examine the relative consistency. Estimation of ICC is used to assess the consistency of the intended measured variable by the use of an instrument for similar individuals in two different situations. A 2-week to 1-month interval between two tests is suitable [26]. In this study, 30 participants were used to determine consistency of the developed instrument so that they completed the final instrument twice with a 2-week interval. Koo \& Li have rendered ICC less than 0.5 as weak, between 0.5 and 0.75 as moderate, between 0.75 and 0.90 as good, and greater than 0.90 as excellent consistency [32] . Ultimately, SEM was used to determine the accuracy of test measurement. SEM is one of indices of 
measurement accuracy that shows an estimation of acceptable expected deviation from real values in a group of measurements in a specific condition, i.e., SD of scores distribution [26]. Moreover, the weight and significance of each item in each factor were determined by the use of results of factor analysis and loading of each item onto that factor [33].

Scoring of instruments is possible on the basis of Likert rules and/or linear transformation method so that the choices open to each item ranged from very much $=5$ to very little $=1$. To determine whether weighting created any changes in the items of the instrument, the mean rank of each item was estimated by paired t-test before and after weighting. Then, the hierarchical position of the item in the instrument was determined in two states based on these mean ranks [33].

\section{Results}

The operational definition of shared governance, characteristics, antecedents, and consequences were extracted from the results of content analysis. According to the findings, shared governance is a unique multi-lateral concept and an eccentric (non-centered) structural model in which all beneficiary parties with contribution-based relations participate as a unique entity in a contributory milieu via understanding the importance of inter-personal conflicts based on spirituality. In such an environment, they are all responsible for their duties. The prerequisite of such governance is the presence of infrastructural factors and committed managers and faculty members in the unique context of higher education who try their best in line with the needs of the modern era. The result of such an attempt will be promotion of organizational commitment and personal and organizational development. Therefore, given the definition of shared governance in this study, it may be asserted that in the Iranian cultural context, this concept was very similar to many other countries except that organizational spirituality was highly emphasized in Iran due to the religious and cultural context of our country and also due to the importance of nursing and midwifery professions that deal with human lives.

In the first part of the study, the results of the two theoretical stages (22 articles) and the qualitative interviews (13 participants) were used to extract the items. There were eight female and five male participants with the youngest being 41 and the oldest being 56 years old. Their work experience ranged from 6-29 years. In addition, their managerial experience showed a range from one to 24 years. All participants, except for one general practitioner, were specialists in nursing school management $[18,22]$.

The results of the hybrid phase led to extraction of 470 primary codes in the theoretical stage and 937 primary codes in the fieldwork phase. These codes were finally classified into 45 subcategories and 14 categories based on semantic similarity, and a general theme labeled "several souls in one body" (Table 1) [18, 22].

Please insert Table 1 here

An inductive- deductive method was used to develop 268 primary items on the basis of the results of the theoretical and interview phases using a 5-point Likert scale without reverse scoring ranging from "very little" 1 to "very much" 5 . After merging the overlapping items by the research team, the instrument entered a qualitative face validation stage with 150 items. After reviewing the participants' opinions by the research team in this phase, 5 out of all items were divided into two separate items and thus a new item was added. In addition, 37 items were omitted due to their great similarity with other items. One item was omitted due to the absence of any part-time faculty members in the nursing schools under study and another item was deleted as it pertained just to faculty clinicians. Next, 6 more items were excluded in the quantitative face validation due to an impact score of less than 1.5. At this stage, the shared governance feasibility instrument entered the content validation stage with 111 items. Given the respondents' comments, some items were modified in the qualitative content validation phase and 23 items were omitted due to their high similarities with other items. Additionally, the item "How far do the school dean and deputies try to empower/develop the staff?" was added. The shared governance instrument was prepared with 89 items to undergo quantitative content validation. Twelve items were deleted in the CVR survey due to a CVR less than 0.60 [34]. The cutoff point was set at 0.80 to determine CVI. Moreover, SCVI was obtained as 0.910 with the mean approach that was appropriate. The inter-rater consensus index was excellent or good for most items. Finally, the instrument entered the construct validation stage with 77 items. The primary reliability of the instrument was estimated before construct validation. Cronbach's alpha of the shared governance instrument with 77 items was 0.975 that was acceptable. Furthermore, the results of item analysis performed in this phase, the correlation among the items and between each item and the whole instrument were calculated. The correlation coefficient of 7 items was less than 0.30 . Thus, the reliability coefficient was estimated even in the case of deletion of the said items. Although Cronbach's alpha of all the related categories reduced after omission of the items, all of these 7 items were deleted by the research team due to increase of total reliability of the instrument to 0.977 . The age of 194 participants in the construct validation ranged between 29 and 61 years. The mean work experience of individuals was less than 20 years. Most participants were female and held a $\mathrm{PhD}$ degree in nursing and worked as assistant professors and most had not taken part in management courses and workshops. The KMO

Page 5/16 
was estimated at 0.953 indicating a sufficient number of samples in factor analysis. Statistical significance of Bartlett's sphericity test $(P=0.000)$ suggested proper conditions of factor analysis. In the next stage, the factors were extracted and the variables with high correlation were put in a class or factor. Also, this study used a scree plot (Figure 2) and cumulative variance percentage determined by the extracted factors.

Please insert Figure 2

The results of factor analysis with promax rotation demonstrated a bi-factorial structure with a total variance of $78.6 \%$ for 52 items of shared governance instrument. Eighteen items were omitted in this stage and the number of items was reduced to 52 . Thus, $44.6 \% 18$ of the common variance was accounted for by the first factor and $3.95 \%$ by the second factor (Table 2).

Please insert Table 2

Labeling of factors was done through a mental, theoretical, and deductive process by considering the dimensions identified during the qualitative stage of the study under the guidance and consultation of the research team. After completing factor analysis and omission of some items, reliability was established again via internal consistency on 194 participants. To examine the internal consistency of the whole instrument, Cronbach's alpha, Omega index, and split-half reliability via the usual and odd/even method were used. The results suggested high internal consistency of the whole questionnaire and all factors (Table 3).

Please insert Table 3

Test-retest method was used to determine instrument stability, with an ICC of 0.911 suggesting high consistency of the instrument with SEM of 10.43 (Table 4).

Please insert Table 4

The questionnaire items were weighted using the formula given above. By comparing the mean weights obtained with both methods of weighted and non-weighted items, paired t-test showed a significant difference between the two methods $(P=0.000, T=48.81)$. Thus, to interpret the results obtained from the scale, it is better to estimate the weighted Likert values. Ultimately, the shared governance feasibility instrument was developed with 52 items and 2 factors of "shared atmosphere and culture" and "infrastructural prerequisites".

\section{Discussion}

This study developed and validated a shared governance feasibility instrument. Although most studies on shared governance have used instruments derived from AAUPISG (The American Association of University Professors Indicators of Sound (Shared Governance), the instrument merely reflects some concepts of the AAUP's 1966 Statement on Government of Colleges and Universities and does not deal with feasibility. Some strong points of the instrument developed in this study include: extraction of items with a inductive-deductive approach (review of literature and interview with faculty members) whereas none of the present instruments are based on faculty members' experiences $[13,14]$. Finnell has recommended that future studies focus on a qualitative study using interviews with individuals to better understand the attitudes of managers [9]. Since any measurement is valid in so far as it measures what it is intended to measure [35], in this study the validation process began with psychometric face validation. The studies abroad on shared governance instrument development have either not discussed face validity $[13,15,19]$ or if they have reported it in papers [14], it seems that they have all used only qualitative face validity, as they did not report quantitative estimation of face validity and item impact index. For example, in the study by Zhang, 10 items were omitted in the qualitative face validation stage. In the next phase, the content validity of the instrument was investigated[14]. The studies abroad on

Page 6/16 
implementation of instruments in examining shared governance have either not reported content validation or if reported, they have used an adjusted form of AAUP instrument of shared governance $[13,14,21]$. This study used EFA with Promax rotation. Factor analysis extracted the structures of the two factors that had acceptable validity and reliability so that the two factors accounted for $78.6 \%$ of the total variance. The first factor, i.e., "shared atmosphere and culture", is in line with the "overall climate for shared governance" that is one characteristic of Ramo's shared governance indicators $[8,12,13,20]$. Indeed, the first three items of the first factor, i.e., reciprocal confidence [11, 19, 20], conciliation and reciprocal understanding [36], and communication [13, 20,37] are in line with the "overall climate for shared governance" index from Ramo's shared governance indicators. The second factor was "infrastructural prerequisites" that, although there was no index with this label, in review of literature or in Ramo's shared governance indicators. There are some items of this factor that are in line with studies that have mentioned the following items as necessary for the successful implementation of shared governance: maintaining acceptable workload for faculty members and having sufficient time for sharing [20], accessibility of information, support, and resources for the staff [9, 38], and also having a positive feeling toward the work environment and moving towards organizational goals [9]. A quantitative study used construct validation of EFA type to adjust the parts of National Survey of Community College Leaders (NSCCL) instrument pertaining to shared governance and satisfaction. In the present study, the shared governance instrument showed proper internal consistency during investigation of reliability in the first stage and during investigation of internal consistency in the second stage. Each item showed high correlation with the whole instrument, indicating that all items measure the same construct. Test-retest was used to explore consistency (stability) of the instrument (Cronbach's alpha) whereas the shared governance instrument used in Finnell (2014) did not deal with this aspect of reliability and has sufficed to examining internal consistency [9].

The shared governance instrument entered the item weighting stage with 52 items. Weighting of items can provide more accurate results [39]. Nevertheless, none of the shared governance instruments abroad has weighed the items $[9,13,14,21]$. In the present study, the mean scores of various factors in the instrument were significantly different before and after weighting. Eventually, the findings revealed that the 52 -item "shared governance instrument" was acceptable in validity and reliability with respect to the two factors.

\section{Limitations:}

One of the limitations of the present study was the difficult access to higher order and intermediary managers of medical universities and their limited free time for interviews in the qualitative stage of the study due to their highly busy condition, which was time-consuming process for interview. Another limitation was the difficult access to faculty members at all nursing schools of major medical universities in Iran for completing the questionnaires. The researchers followed up the deficient questionnaires frequently in order to decrease this limitation as much as possible.

\section{Conclusion}

Hybrid content analysis showed that shared governance is like "several souls in one body" in the Iranian cultural context with its emphasis on all aspects of organizational contribution, ethics, and spirituality. Managers of higher education and nursing schools should pay due attention to all aspects of shared governance, especially spirituality in managing their organizations. In addition, the findings showed that this instrument has acceptable validity and reliability, and confirmed construct validity in the two-factor model. This instrument

can be used by nursing school managers to measure the feasibility of the shared governance in their organization. Managers and policymakers at the level of the related ministry of health and medical universities and affiliated nursing schools are advised to apply the results of this study to prepare for revising their centralized management policies and move forward decentralization and independence. They should make decisions at the macroscopic and microscopic levels to increase contribution of all beneficiaries and interested parties. It appears that providing infrastructural prerequisites for implementing shared governance would not only lead to the use of intelligence and capacities of beneficiaries and faster movement toward achieving organizational goals, but also serve as a practical guide for institutionalizing student participation in various professional and social fields in future.

\section{Implications for nursing management}

The results demonstrated that, except one item that pertained to faculty clinicians, all items of the developed shared governance instrument are designed in a way that provide a highly clear attitude of implementing shared governance to policy-makers, higher education centers, and managers. It is also hoped that this study and the developed instrument can serve as guide for the feasibility of implementing shared governance to assess management styles and performance in higher education centers.

\section{List Of Abbreviations}

AAUP: American Association of University Professors; AAUPISG: The American Association of University Professors' Indicators of Sound Governance; CVR: Content validity Ratio; CVI: Content validity Index; SEM: Standard Error of Measurement; EFA: Exploratory Factor Analysis; 
KMO: Kaiser-Meyer-Olkin; ICC: Intra class correlation

\section{Declarations}

\section{Ethics approval and consent to participate}

\section{Ethical considerations}

The Ethics Committee of Shahid Beheshti University of Medical Sciences approved the research (code: IR.SBMU.REC.2016.84). The participants joined the study under voluntary conditions and could leave the study at any stage. The researcher elucidated the research goals and procedures to the participants assured that principles of anonymity and confidentiality of information would be observed.

Consent for Publication: Not applicable.

Availability of Data and Materials: Not applicable.

Competing Interests: The authors have no competing interests to declare.

Funding: This research is part of PhD thesis and did not receive any grant from funding agencies in the public, commercial, or not-for-profit sectors.

Author Contributions: Contribution Details (to be ticked marked as applicable): 


\begin{tabular}{|c|c|c|c|c|c|c|c|}
\hline \multicolumn{2}{|l|}{ - } & $\begin{array}{l}\text { Contributor } \\
1\end{array}$ & $\begin{array}{l}\text { Contributor } \\
2\end{array}$ & $\begin{array}{l}\text { Contributor } \\
3\end{array}$ & $\begin{array}{l}\text { Contributor } \\
4\end{array}$ & $\begin{array}{l}\text { Contributor } \\
5\end{array}$ & $\begin{array}{l}\text { Contributor } \\
6\end{array}$ \\
\hline \multirow{9}{*}{$\begin{array}{l}\text { Conception } \\
\text { and } \\
\text { design, or } \\
\text { acquisition of } \\
\text { data, or } \\
\text { analysis and } \\
\text { interpretation } \\
\text { of data }\end{array}$} & Concepts & $\checkmark$ & $\checkmark$ & $\checkmark$ & $\checkmark$ & $\checkmark$ & \\
\hline & Design & $\checkmark$ & $\checkmark$ & $\checkmark$ & $\checkmark$ & $\checkmark$ & \\
\hline & $\begin{array}{l}\text { Definition of } \\
\text { intellectual } \\
\text { content }\end{array}$ & $\checkmark$ & $\checkmark$ & $\checkmark$ & & & \\
\hline & $\begin{array}{l}\text { Literature } \\
\text { search }\end{array}$ & $\checkmark$ & & $\checkmark$ & & & \\
\hline & $\begin{array}{l}\text { Clinical } \\
\text { studies }\end{array}$ & $\checkmark$ & $\checkmark$ & $\checkmark$ & & & \\
\hline & $\begin{array}{l}\text { Experimental } \\
\text { studies }\end{array}$ & $\checkmark$ & & $\checkmark$ & & & \\
\hline & $\begin{array}{l}\text { Data } \\
\text { acquisition }\end{array}$ & $\checkmark$ & & $\checkmark$ & & & \\
\hline & $\begin{array}{l}\text { Data } \\
\text { analysis }\end{array}$ & $\checkmark$ & $\checkmark$ & $\checkmark$ & $\checkmark$ & $\checkmark$ & \\
\hline & $\begin{array}{l}\text { Statistical } \\
\text { analysis }\end{array}$ & $\checkmark$ & & $\checkmark$ & & & \\
\hline \multirow{2}{*}{$\begin{array}{l}\text { Drafting the } \\
\text { article or } \\
\text { revising it } \\
\text { critically for } \\
\text { important } \\
\text { intellectual } \\
\text { content }\end{array}$} & $\begin{array}{l}\text { Manuscript } \\
\text { preparation }\end{array}$ & $\checkmark$ & $\checkmark$ & $\checkmark$ & $\checkmark$ & $\checkmark$ & $\checkmark$ \\
\hline & $\begin{array}{l}\text { Manuscript } \\
\text { editing }\end{array}$ & $\checkmark$ & $\checkmark$ & $\checkmark$ & $\checkmark$ & $\checkmark$ & $\checkmark$ \\
\hline \multirow{2}{*}{$\begin{array}{l}\text { Final } \\
\text { approval of } \\
\text { the version to } \\
\text { be published }\end{array}$} & $\begin{array}{l}\text { Manuscript } \\
\text { review }\end{array}$ & $\checkmark$ & $\checkmark$ & $\checkmark$ & $\checkmark$ & $\checkmark$ & $\checkmark$ \\
\hline & Guarantor & $\checkmark$ & $\checkmark$ & $\checkmark$ & $\checkmark$ & $\checkmark$ & $\checkmark$ \\
\hline
\end{tabular}

\section{Acknowledgements}


The research team gives their special thanks to all authorities, faculty members, and staff at all nursing schools affiliated to Shahid Beheshti University of Medical Sciences for their cooperation, especially Dr. Armin Zareian and Dr. Abbas Ebadi for their support during all stages of the study. We would also like to acknowledge the deputy-in-research at this university for approving the research proposal. Finally, the authors would like to thank Dr. Rodney Falk for editing this manuscript.

\section{References}

1. Akright JA, Crabtree JL: Shared governance in the academic environment. Nursing management 2019, 50(7):10-11.

2. Sullivan LK: Staff Engagement within an Academic Shared Governance Model for Nursing Education: An Evaluation Study. University of Southern California; 2018.

3. Derakhshan R, Turner R, Mancini M: Project governance and stakeholders: a literature review. International Journal of Project Management 2019, 37(1):98-116.

4. Wise G, Dickinson C, Katan T, Gallegos MC: Inclusive higher education governance: managing stakeholders, strategy, structure and function. Studies in Higher Education 2020, 45(2):339-352.

5. Pishgooie AH, Rahimi A, Khaghanizadeh M: Experiences of Iranian nursing faculty members on working in conflict climate. Iranian Red Crescent Medical Journal 2016, 18(1):e20319.

6. Jones WA: Faculty involvement in institutional governance: A literature review. Journal of the Professoriate 2011, 6(1):118-135.

7. Barden AM, Griffin MTQ, Donahue M, Fitzpatrick JJ: Shared governance and empowerment in registered nurses working in a hospital setting. Nursing administration quarterly 2011, 35(3):212-218.

8. Anderson SD: Shared Governance Shane D. Anderson RN, BSN, MDIV November 2012. 2012.

9. Finnell JT: Shared governance and job satisfaction effecting community college leaders. San Diego State University; 2014.

10. Owen D, Boswell C, Opton L, Franco L, Meriwether C: Engagement, empowerment, and job satisfaction before implementing an academic model of shared governance. Applied Nursing Research 2018, 41:29-35.

11. Tierney WG: Research Excellence in Indian Higher Education: An American Perspective. Social Change 2016, 46(2):277-285.

12. Taylor M: Shared governance in the modern university. Higher Education Quarterly 2013, 67(1):80-94.

13. Shah S, Zai SY, Munshi P, Asimiran S, Pihie ZAL, Ahmad S: A study to evaluate the attitude of faculty members of public universities of Pakistan towards shared governance. Research on Humanities and Social Sciences 2014, 4(1):16-22.

14. Zhang D: A Comparison of Perceptions and Implementation of Shared Governance between American and Chinese Higher-Education Institutions. East Tennessee State University; 2013.

15. Abdelkader R, Al-Hussami MO, Saleh A, Shath TA: Perception of academic nursing staff toward shared governance. Journal of Nursing Education and Practice 2012, 2(3):46.

16. Baker-Brown CM: An analysis of the shared governance practices in the Jamaican community college system: Faculty perspectives. Morgan State University; 2011.

17. Francis-Johnson P, Harkness L, Pritchard A, Pullen Jr RL: Seven steps to academic shared governance. Nursing2020 2018, 48(10):11-14.

18. Sattarzadeh-Pashabeig M, Atashzadeh-Shoorideh F, Sadoughi M-M, Khachian A, Zagheri-Tafreshi M: Characteristics of Shared Governance in Iranian Nursing Schools: Several Souls in One Body. Iranian journal of nursing and midwifery research 2018, 23(5):344.

19. Stuart TR: A study of the relationship between self-perceived presidential leadership style and the level of faculty satisfaction with shared governance at community colleges: Ohio University; 2012.

20. Ramo K: Indicators of sound governance. From 1986 Monograph: American Association of University Professors 2001.

21. Tiede J: Report on the 2010 Illinois Wesleyan University shared governance survey. 2010.

22. Atashzadeh-Shoorideh F, Sadoughi M-M, Sattarzadeh-Pashabeig M, Khachian A, Zagheri-Tafreshi M: Factors predisposing to shared governance: a qualitative study. BMC nursing 2019, 18(1):9.

23. Schwartz-Barcott D: An expansion and elaboration of the hybrid model of concept development. Concept Development in Nursing Foundations, Techniques, and Applications 2000:129-159.

24. Graneheim UH, Lundman B: Qualitative content analysis in nursing research: concepts, procedures and measures to achieve trustworthiness. Nurse education today 2004, 24(2):105-112.

25. Rodgers BL, Knafl KA: Introduction to concept development in nursing. Concept development in nursing: Foundations, techniques, and applications 2000:1-6.

26. Waltz CF, Strickland OL, Lenz ER: Measurement in nursing and health research. Springer Publishing Company.; 2010. 
27. Colton D, Covert RW: Designing and constructing instruments for social research and evaluation: John Wiley \& Sons; 2007.

28. Polit D, Beck C: Nursing research: Generating and assessing evidence for nursing practice; 2008. 10th: Philadelphia: Lippincott Williams \& Willkins Co; 2017.

29. Plichta SB, Kelvin EA, Munro BH: Munro s statistical methods for health care research: Wolters Kluwer Health/Lippincott Williams \& Wilkins; 2013.

30. Hayton JC, Allen DG, Scarpello V: Factor retention decisions in exploratory factor analysis: A tutorial on parallel analysis. Organizational research methods 2004, 7(2):191-205.

31. Knapp TR, Brown JK: Ten measurement commandments that often should be broken. Research in Nursing \& Health 1995, 18(5):465-469.

32. Koo TK, Li MY: A guideline of selecting and reporting intraclass correlation coefficients for reliability research. Journal of chiropractic medicine 2016, 15(2):155-163.

33. Creswell JW, Clark VLP: Designing and conducting mixed methods research: Sage publications; 2017.

34. Lawshe $\mathrm{CH}$ : A quantitative approach to content validity 1. Personnel psychology 1975, 28(4):563-575.

35. Polit DF, Beck CT: Essentials of nursing research: Appraising evidence for nursing practice: Lippincott Williams \& Wilkins; 2010.

36. Cramer SF: Shared Governance in Higher Education, Volume 1: Demands, Transitions, Transformations, vol. 1: SUNY Press; 2017.

37. The corporatization of shared governance: The corporate challenge and the Academic Response [ http://system.suny.edu/media/suny/content-assets/documents/faculty-senate]

38. Crellin MA: The future of shared governance. New Directions for Higher Education 2010, 2010(151):71-81.

39. Creswell JW, Plano Clark V: Choosing a mixed methods design. Designing and conducting mixed methods research 2011:53-106.

\section{Tables}


Table 1: Integrated categories and subcategories of theoretical stage and field work

\begin{tabular}{|c|c|c|}
\hline Subcategories & Category & \\
\hline $\begin{array}{ll}\text { - } & \text { Uniqueness of schools/higher education Centers } \\
\text { - } & \text { Uniqueness of faculty members } \\
\text { - } & \text { Uniqueness of nursing education } \\
\end{array}$ & $\begin{array}{l}\text { Participatory context of higher education } \\
\text { institutions }\end{array}$ & \multirow[t]{4}{*}{ Antecedents } \\
\hline $\begin{array}{ll}- & \text { Facilitative rules of participation } \\
\text { - } & \text { Corresponding intra-organizational support } \\
\text { - } & \text { Resources suitable for work } \\
\text { - } & \text { Learning the team work } \\
\end{array}$ & Infrastructural obligations & \\
\hline $\begin{array}{ll}\text { - } & \text { Members' needs } \\
\text { - } & \text { Managers' needs } \\
\text { - } & \text { Organizations' requirements } \\
\end{array}$ & $\begin{array}{l}\text { Coordination with contemporary } \\
\text { requirements }\end{array}$ & \\
\hline 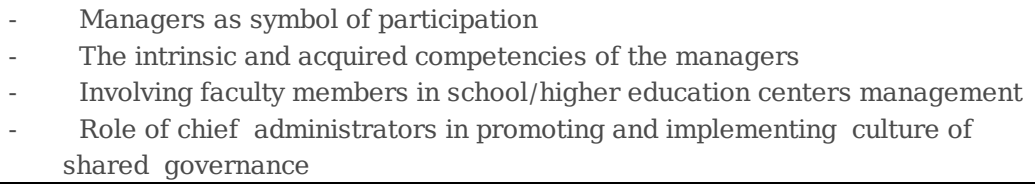 & Participation-oriented managers & \\
\hline $\begin{array}{ll}- & \text { Adaptation to change } \\
- & \text { Common goals } \\
- & \text { Mutual respect } \\
- & \text { Equality among stakeholders } \\
- & \text { Coordination } \\
- & \text { Mutual trust } \\
- & \text { Empathy }\end{array}$ & Participatory Climate and Culture & \multirow[t]{7}{*}{ Characteristics } \\
\hline $\begin{array}{ll}\text { - } & \text { Participatory decision-making } \\
\text { - } & \text { Participatory understanding } \\
\text { - } & \text { Transparent exchange of organizational knowledge }\end{array}$ & Conscious participatory decision-making & \\
\hline $\begin{array}{l}\text { Accountability of all the stakeholders } \\
\text { Importance of accountability }\end{array}$ & Mutual accountability & \\
\hline $\begin{array}{l}\text { Necessity of conflict } \\
\text { Conflict management }\end{array}$ & Multiplicity of the ideas & \\
\hline $\begin{array}{l}\text { Participatory structure } \\
\text { Participatory organizational culture } \\
\text { Continuous participation }\end{array}$ & Decentralized structure & \\
\hline $\begin{array}{l}\text { Communication as a key factor } \\
\text { Open vertical and horizontal communication } \\
\text { Establishment of appropriate formal and informal relations }\end{array}$ & Interrelationship & \\
\hline $\begin{array}{l}\text { Spiritual goals } \\
\text { Promotion of religious ethical values } \\
\text { Following religious guidelines }\end{array}$ & Sublime organization & \\
\hline $\begin{array}{l}\text { Members' satisfaction } \\
\text { Organizational attachment }\end{array}$ & Promotion in Organizational Commitment & \multirow[t]{3}{*}{ Consequences } \\
\hline $\begin{array}{l}\text { Faculty members' autonomy } \\
\text { Blooming the talents }\end{array}$ & Individual Development & \\
\hline $\begin{array}{l}\text { School dynamics } \\
\text { Increasing Productivity } \\
\text { Promotion of the Institute's ethics and culture } \\
\text { Power distribution }\end{array}$ & Organizational Development & \\
\hline
\end{tabular}

Table 2: Factors extracted by factor analysis by promax rotation and factor loadings of items of each factor in shared governance instrument 


\begin{tabular}{|c|c|c|c|c|}
\hline $\begin{array}{l}\text { Cumulative } \\
\text { variance } \\
\text { percentage }\end{array}$ & $\begin{array}{l}\text { Item } \\
\text { no. }\end{array}$ & Item & $\begin{array}{l}\text { First } \\
\text { factor }\end{array}$ & $\begin{array}{l}\text { Seconc } \\
\text { Factor }\end{array}$ \\
\hline \multirow{4}{*}{$\begin{array}{l}\text { First factor } \\
\text { Shared governance } \\
\text { atmosphere } \\
\text { and culture }\end{array}$} & 1 & $\begin{array}{l}\text { How much reciprocal confidence exists between school "dean and deputies" } \\
\text { and faculty members? }\end{array}$ & 0.9 & \\
\hline & 2 & $\begin{array}{l}\text { How much is the behavior of school dean and deputies associated with } \\
\text { affability and conciliation at the time of trouble for educational ward } \\
\text { managers? }\end{array}$ & 0.875 & \\
\hline & 3 & $\begin{array}{l}\text { How much formal and organized communication is there between faculty } \\
\text { members and school dean and deputies? }\end{array}$ & 0.856 & \\
\hline & 4 & How much effort is made by school dean and deputies to empower the staff? & 0.825 & \\
\hline \multirow[t]{22}{*}{$\begin{array}{l}\text { Variance } \\
\text { percentage }=44.618\end{array}$} & 5 & $\begin{array}{l}\text { How much effort is made by school dean and deputies to empower the faculty } \\
\text { members? }\end{array}$ & 0.800 & \\
\hline & 6 & $\begin{array}{l}\text { How much importance is attached to criticisms and recommendations received } \\
\text { from criticisms box by the school dean and deputies? }\end{array}$ & 0.779 & \\
\hline & 7 & $\begin{array}{l}\text { How much is the performance of school dean and deputies in line with school } \\
\text { goals? }\end{array}$ & 0.776 & \\
\hline & 8 & $\begin{array}{l}\text { How much are school dean and deputies competent in managing } \\
\text { conflict/approaching opposite opinions? }\end{array}$ & 0.773 & \\
\hline & 9 & $\begin{array}{l}\text { How much reciprocal respect is there between and among the beneficiary } \\
\text { groups in the school? }\end{array}$ & 0.773 & \\
\hline & 10 & $\begin{array}{l}\text { How much collaboration and coordination is there between all beneficiaries, } \\
\text { especially between faculty members and school dean and deputies? }\end{array}$ & 0.756 & \\
\hline & 11 & How much feeling of equality is there between school staff and managers? & 0.745 & \\
\hline & 12 & How much effort is made by school dean and deputies to empower students? & 0.726 & \\
\hline & 13 & $\begin{array}{l}\text { What is the rate of application of informal and friendly rapport that supports } \\
\text { sharing by school dean and deputies? }\end{array}$ & 0.724 & \\
\hline & 14 & $\begin{array}{l}\text { How much effort is made by school dean, deputies, and faculty members to } \\
\text { clarify the reasons of their decisions about others? }\end{array}$ & 0.714 & \\
\hline & 15 & How much distribution of power exists in the school? & 0.713 & \\
\hline & 16 & $\begin{array}{l}\text { How far are school dean and deputies responsible for shared decision- } \\
\text { makings? }\end{array}$ & 0.710 & \\
\hline & 17 & How humanly are the relations among beneficiaries? & 0.637 & \\
\hline & 18 & $\begin{array}{l}\text { How far have school dean and deputies been able to align individual goals of } \\
\text { beneficiaries with organizational goals? }\end{array}$ & 0.630 & \\
\hline & 19 & $\begin{array}{l}\text { How far are programs by faculty members for managing school affairs } \\
\text { celebrated and supported by school dean and deputies? }\end{array}$ & 0.630 & \\
\hline & 20 & $\begin{array}{l}\text { How far is contribution of school dean and deputies based on staff } \\
\text { capabilities? }\end{array}$ & 0.618 & \\
\hline & 21 & $\begin{array}{l}\text { How much do school dean and deputies verbally and practically propagate the } \\
\text { contributory culture in the school? }\end{array}$ & 0.617 & \\
\hline & 22 & $\begin{array}{l}\text { How much is the behavior of educational ward managers associated with } \\
\text { affability, conciliation, and reciprocal understanding at the times of trouble? }\end{array}$ & 0.581 & \\
\hline & 23 & $\begin{array}{l}\text { How far do school dean and deputies cooperate with affiliated hospitals and } \\
\text { healthcare centers to investigate educational, research, and managerial } \\
\text { problems of clinical setting? }\end{array}$ & 0.527 & \\
\hline & 24 & $\begin{array}{l}\text { How much free space is there for faculty members to pose and discuss their } \\
\text { scientific questions? }\end{array}$ & 0.510 & \\
\hline & 25 & $\begin{array}{l}\text { How much importance is attached to compatibility of affairs with } \\
\text { environmental changes (social, technological, economical, and political) by } \\
\text { higher order and intermediary managers for shared management of school } \\
\text { affairs? }\end{array}$ & 0.510 & \\
\hline & 26 & How much transfer of power and delegation is there for implementing shared & 0.483 & \\
\hline
\end{tabular}

Page 13/16 


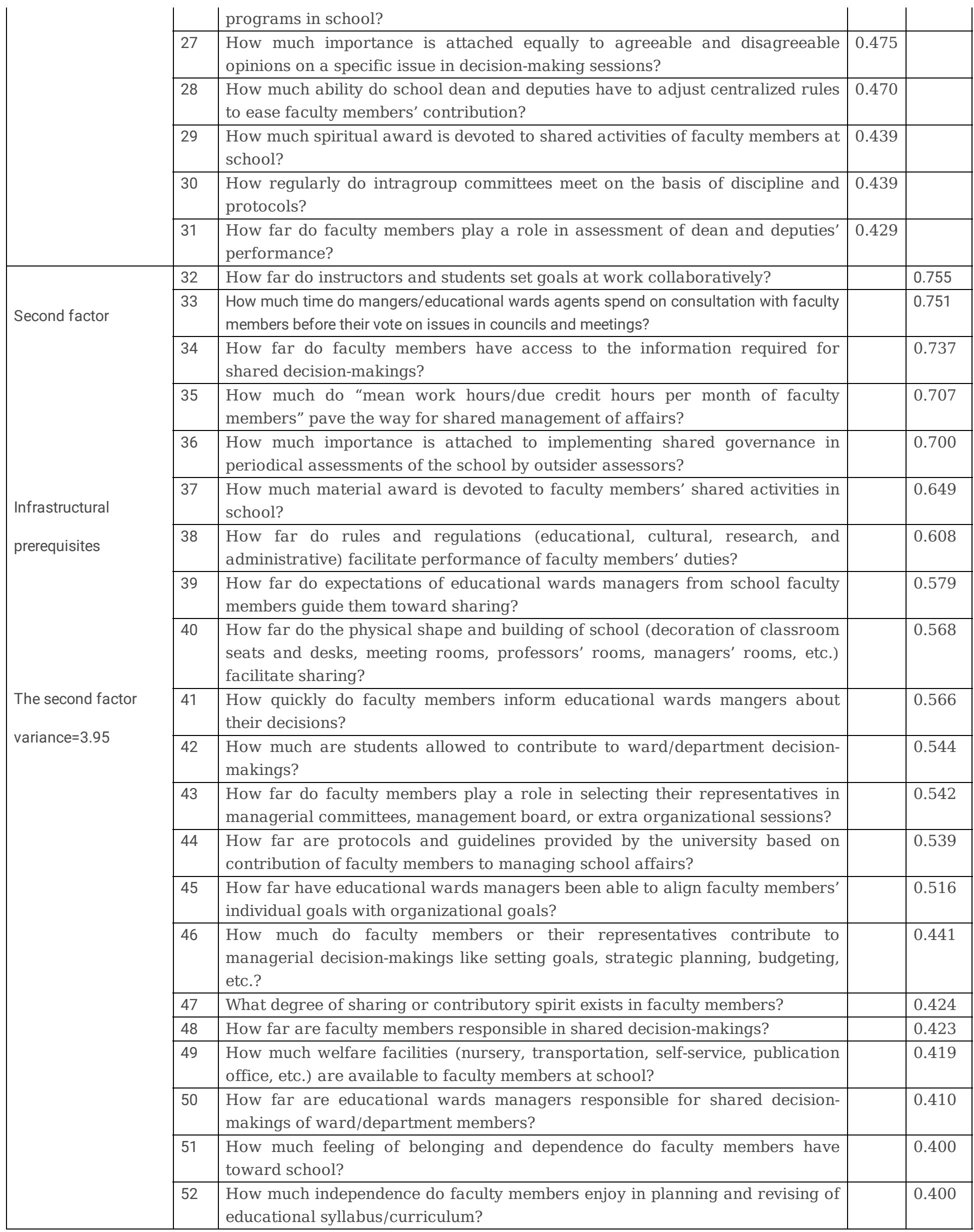


Table 3: Internal consistency of shared governance instrument after factor analysis

\begin{tabular}{|l|l|l|l|l|l|l|}
\hline $\begin{array}{l}\text { Factor } \\
\text { number }\end{array}$ & Factor name of & $\begin{array}{l}\text { Number } \\
\text { items }\end{array}$ & $\begin{array}{l}\text { Cronbach's } \\
\text { alpha }\end{array}$ & Omega & $\begin{array}{l}\text { Ordinary Split- } \\
\text { half }\end{array}$ & $\begin{array}{l}\text { Odd/even } \\
\text { half }\end{array}$ \\
\hline 1 & $\begin{array}{l}\text { Shared atmosphere and } \\
\text { culture }\end{array}$ & 31 & 0.972 & 0.802 & \\
\hline 2 & Infrastructural prerequisites & 21 & 0.930 & 0.716 & & \\
\hline Total
\end{tabular}

Table 4: Examination of consistency of shared governance instrument

\begin{tabular}{|l|l|l|l|l|}
\hline Factor & Mean (SD) & ICC & Cl (95\%) & SEM \\
\hline 1 & $80.844(23.941)$ & 0.897 & $(0.792-0.949)$ & 7.683 \\
\hline 2 & $56.796(15.192)$ & 0.908 & $(0.815-0.955)$ & 4.607 \\
\hline Total & $137.963(34.963)$ & 0.911 & $(0.821-0.956)$ & 10.43 \\
\hline
\end{tabular}

\section{Figures}

\begin{tabular}{|c|c|c|}
\hline $\begin{array}{c}\text { Qualitative phase } \\
\text { (Hybrid concept analysis) }\end{array}$ & Quantitative phase & \\
\hline $\begin{array}{l}\text { 1. Theoretical stage: content } \\
\text { analysis of literatures( } \mathrm{n}=22 \\
\text { articles) } \\
\text { 2. Filed practice: content } \\
\text { analysis of participants' } \\
\text { interview ( } \mathrm{n}=13 \text { participants) } \\
\text { 3. Final analysis: Integration of } \\
\text { codes (1407) and sub- } \\
\text { categories ( } 45) \text { to find the } \\
\text { definition of shared } \\
\text { governance and its antecedents } \\
\text { ( } 4 \text { categories), characteristics } \\
\text { ( } 7 \text { categories), and } \\
\text { consequences ( } 3 \text { categories) }\end{array}$ & $\begin{array}{l}\text { 1. Item generation based on } \\
\text { hybrid phase ( } 150 \text { items) } \\
\text { 2. Face validity }(\mathrm{n}=10) \\
\text { 3. Content validity }(\mathrm{n}=10) \\
\text { 4. Exploratory factor analysis } \\
(\mathrm{n}=194 \text { participants; } 70 \text { items) } \\
\text { 5. Reliability (primary check: } \\
\mathrm{n}=30 \text {; final check: } \mathrm{n}=194 \\
\text { participants) }\end{array}$ & $\begin{array}{c}\text { Shared } \\
\text { Governance } \\
\text { Feasibility } \\
\text { Instrument } \\
\text { in Nursing } \\
\text { Schools } \\
52 \text { items in } \\
\text { two factors }\end{array}$ \\
\hline
\end{tabular}

Figure 1

Stages of this sequential exploratory mixed method study 


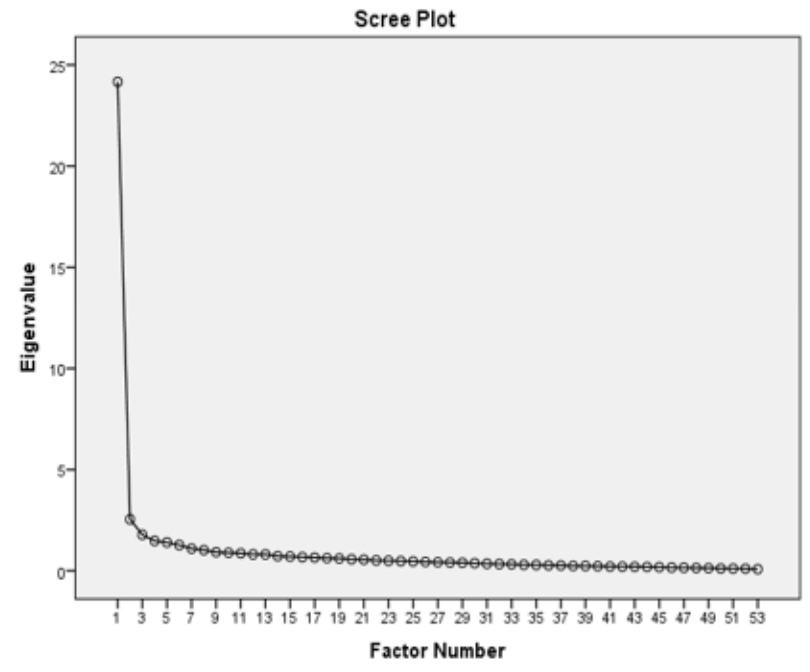

Figure 2

The scree plot of the shared governance instrument 